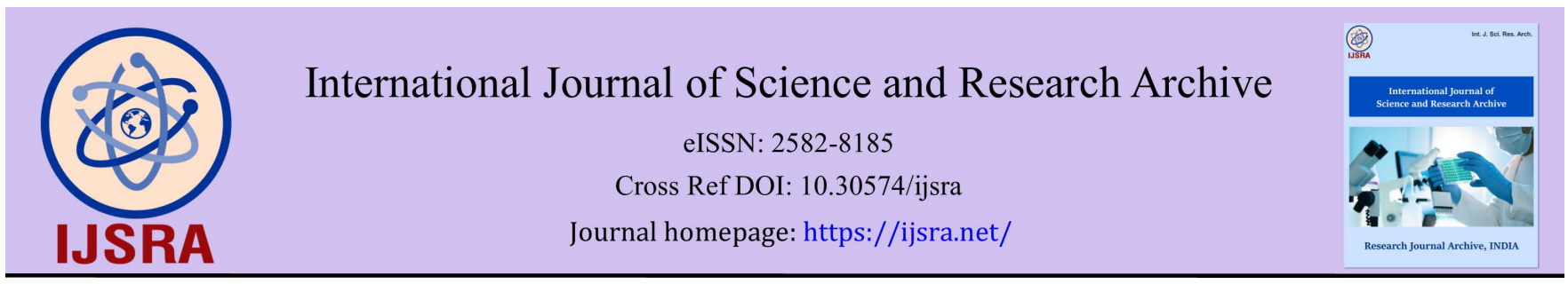

(RESEARCH ARTICLE)

Check for updates

\title{
Study of coinfection of Salmonella typhi, Salmonella paratyphi with Candida spp., in four hospitals of Douala- Cameroon
}

\author{
Alex Morel Longue Essoua 1, Fabrice Fabien Dongho Dongmo ${ }^{1}$, Martin Luther Mogtomo Koanga ${ }^{1}$, Raymond \\ Simplice Mouokeu ${ }^{3}$, Jean Paul Assam Assam ${ }^{2,}{ }^{*}$, Rosalie Anne Ngono Ngane ${ }^{1}$ and Véronique Penlap \\ Nintchom 4 \\ 1 Department of Biochemistry, Faculty of Science, University of Douala, PO Box. 24157 Douala, Cameroon. \\ 2 Department of Microbiology, Faculty of Science, University of Yaoundé I, PO Box. 337 Yaoundé, Cameroon. \\ ${ }^{3}$ Institute of Fisheries and Aquatic Sciences, University of Douala, PO Box. 7236 Douala Bassa, Cameroon. \\ ${ }^{4}$ Department of Biochemistry, Faculty of Science, University of Yaoundé I, PO Box. 812 Yaoundé, Cameroon.
}

International Journal of Science and Research Archive, 2021, 02(02), 110-119

Publication history: Received on 01 March 2021; revised on 30 April 2021; accepted on 03 May 2021

Article DOI: https://doi.org/10.30574/ijsra.2021.2.2.0041

\begin{abstract}
Candida spp., are saprophytic yeasts capable of creating a favorable environment for bacterial infection, amplifying or inhibiting their activity. On the other hand, bacteria produce molecules that reduce the proliferation of Candida spp or promote their adherence to surfaces. The resurgence of typhoid and paratyphoid fevers in endemic individuals and the relative effectiveness of contemporary conventional therapies arouse curiosity to explore other factors that may influence, the re-emergence of infection in patients. We carried out a cross-sectional study of 2500 patients in four hospitals in the city of Douala, Cameroon, from January to December 2019, to determine the influence of Candida spp., on the onset of these infections in patients. Widal and Felix test was used to form the sample, culture on specific media and microscopy confirmed the identity of Salmonella typhi, Salmonella paratyphi and Candida spp. Biochemical tests on a classic tube gallery revealed the biochemical characteristics of bacteria. The results showed that infection with $S$. typhi is predominant, $32.76 \%$ versus $18.4 \%$ of $S$. paratyphi infection. Infection with Candida spp., would increase 4-5 times the frequency of infection with $S$. typhi and S. paratyphi, respectively from $3.08 \%$ to $26.03 \%$, and from $7.08 \%$ to 32.76 $\%$. The presence of Candida spp increases the risk of reoccurrence of $S$. typhi and $S$. paratyphi in patients.
\end{abstract}

Keywords: S. typhi; S. paratyphi; Candida spp; Coinfection; Re-emergence

\section{Introduction}

Candida spp. are commensal saprophytic yeasts in humans, localized on the skin and mucous membranes. This germ becomes pathogenic following in the balance between the yeast's capacity for colonization, the expression of virulence factors and the control by the immune system's defenses. Candida albicans accounts for at least $50 \%$ of all yeast infections and is the fourth leading cause of death, between 1 and $8 \%$ of systemic infections [1]. This risk is increased when they are associated with bacteria or other microorganisms in multicellular structures known as mixed biofilms, which constitute infectious reservoirs for bacteria and yeasts, making diagnosis and therapy difficult $[2,3]$.

Indeed, biofilms are the site of synergistic and inhibitory relationships, allowing for their stability, control of competition for nutrients and infection of new sites [4]. These mechanisms are modulated by molecular factors promoting intercellular communication such as the N-acylhomoserine lactones (AHL) derivative, observed in gramnegative bacteria, or an auto-inducing system 2 (AI-2) common to all bacteria [5, 6].

\footnotetext{
* Corresponding author: Jean Paul Assam Assam

Department of Microbiology, Faculty of Science, University of Yaoundé I, PO box. 337 Yaoundé.

Copyright (C) 2021 Author(s) retain the copyright of this article. This article is published under the terms of the Creative Commons Attribution Liscense 4.0.
} 
The interaction between bacteria and yeasts, particularly Candida albicans, is well documented. This is the case of: «the improved adhesion of yeast to the bladder mucosa by Escherichia coli during certain urinary tract infections» [7]; «the fixation of Pseudomonas aeruginosa and Staphylococcus epidermidis on yeast» [3,8]; "the inhibition of Candida albicans hyphae through the production of competency stimulating peptides (CSPs) by Streptococcus mutans» [9]; «the stimulation of Staphylococcus aureus in the biofilm by prostaglandin E2 (PGE2) produced by C. albicans» [10]; « the stimulation and amplification of $S$. aureus infection by $C$. albicans» [11]; «the increased risk of bacterial co-infection 3.2 times higher in the presence of filamentous fungal keratitis» [12].

The re-emergence of typhoid and paratyphoid fevers caused by $S$. typhi and S. paratyphi in patients from endemic areas raises questions about the mechanisms of infection and resistance of the pathogens involved. Endogenous factors of the infection, beyond contamination through water and foods soiled by stool (sick or asymptomatic carriers) are considered. They affect about 20.000.000 people/year and are responsible for more than 600.000 deaths per year [13]. In Africa, in particular S. typhi infects 10 to more than 100 cases per 100.000 inhabitants [14].

Could the re-emergence of typhoid and paratyphoid fevers in subjects in endermal areas not be endogenous to the human host? The interaction between $S$. typhi, S. paratyphi and candida spp., would contribute to the re-emergence of typhoid fever or paratyphoid fever in patients. The objective of this study is to investigate the relationship between $S$. typhi, S. paratyphi - candida spp.

\section{Material and methods}

\subsection{Study site, sampling and biological material}

The cross-sectional and prospective study ran from January to December 2019. It was carried out on 2500 patients, selected for the study according to the accidental sampling method, during their consultation for any diarrheal disease. After having responded to criteria inclusion such as having a recurrent history of typhoid fever, residing in the Douala area for at least 3 months and being between 11-70 years old, they had to be referred to the diagnosis of typhoid fever.

The district hospitals of Deido (HDD), Bonassama (HDB), Nylon Brazzaville (HDN) and the Military Hospital of Coastal Region II (HMR2) were the place of sample collection based on a questionnaire whose focus was mainly on the recurrence of the disease in patients and the absence of an immunosuppressive pathology. These health establishments were chosen for their geographical location allowing them to accommodate a more heterogeneous population, representing the miniature city of Douala, from the point of view of the cosmopolitan character, the low level of accessibility to drinking water and questionable compliance with basic hygiene rules.

The biological material consisted of serum and stool collected from patients, assigned for diagnosis of typhoid fever after consultation by a physician. The age interval made it possible to exclude cases of re-emergence of the disease related to the moral immaturity of hygiene of the patients ( $<11$ years old) or the aging of the immune system ( $>70$ years old). The Institutional Ethics Committee for Research for Human Health at the University of Douala issued the ethical clearance document registered at number 1658 CEI-Udo / 06/2018 / T. Data collection in hospitals has been authorized under to № 2798 / AR / MISANTE / DRSPL / BCASS by the Littoral Regional Health Delegation.

\subsection{Search for anti-Salmonella antibodies}

The detection of anti-O and anti-H agglutinins directed against $S$. typhi and $S$. paratyphi in the diluted serum of patients was done by the Widal and Felix test. The positive cases were selected according to the titles of $S$. typhi $\leq 1 / 400$ and $S$. paratyphi $\geq 1 / 1600$ ), according to the approved standards of the World Health Organization [13].

\subsection{Isolation and identification of $S$. typhi and $S$. paratyphi}

Isolation of S. typhi and S. paratyphi was performed according to the WHO protocol [13]. A stock suspension of the inoculum was pre-enriched for 24 hours by dilution of $25 \mathrm{~g}$ of stool in $225 \mathrm{~mL}$ of buffered peptone water. Then the mixture was enriched with selenite broth for 24 hours. This step was followed by inoculation on Salmonella-Shigella gelose (SS Agar) and then on Hektoen medium within 24 hours. The Gram control test combined with light microscopy confirmed the Gram-negative character of the bacteria. The differentiation of the strains in the culture medium was completed by the biochemical tests in the classical gallery tube: gas detection (GAS positive), hydrogen sulfide production $\left(\mathrm{H}_{2} \mathrm{~S}\right.$ positive), glucose fermentation (glucose positive), absence of lactose fermentation (lactose negative) by Kliger Hajna test; absence of $\beta$-galactosidase (ONPG negative); detection of decarboxylase (LDC, ODC) and 
dihydrolase $(\mathrm{ADH})$; determination of urease and indole according to the Fergusson method (urease and indole negative).

\subsection{Isolation and identification of Candida spp.}

Stool collected on an empty stomach in the morning in a sterile box was delivered directly to the bench within a maximum of 2 hours for diagnosis. $25 \mathrm{~g}$ of stool was added to $225 \mathrm{~mL}$ of Peptonneous water for the preparation of the initial suspensions according to NF EN ISO 6887-1(2017). $10 \mathrm{~mL}$ of the sample were introduced into the mixture potash $10 \%+$ gycerol $10 \mathrm{~mL}+80 \mathrm{~mL}$ deionized water, and left to stand $+4^{\circ} \mathrm{C}$. After $15 \mathrm{~min}$, the yeasts and mycelial filaments were observed under an optical microscope, stained with May Grunwald Giemsa [15]. Another stool of equal mass was introduced into $9 \mathrm{~mL}$ of $\mathrm{NaCl}$ solution of weight concentration $8.5 \mathrm{~g} / \mathrm{L}$, contained in a test tube, initially centrifuged at $1200 \mathrm{rpm}$ for $15 \mathrm{~min}$. Using a sterile loop, an extract of the medium was inoculated onto a sabouraud medium and the reading was taken 24 hours later after incubation at $37^{\circ} \mathrm{C}$. A control test was carried out to determine the biochemical aspect of the yeast wall, gram-positive using the Gram test.

\subsection{Statistical analysis}

Frequencies, Chi-square and Cramer's index were analyzed using the descriptive statistics method with SPSS 23.0 software, at 0.05 significance level. The correlation of the transformed values, the discrimination measure and the attached diagram of the modality points were highlighted by the factorial analysis of the multiple components.

\section{Results and discussion}

\subsection{Frequency of distribution of typhoid, paratyphoid fevers and candidiasis}

Table (1) shows the distribution of S. typhi, S. paratyphi and Candida spp., by gender and hospital on 2.500 patients, 661 were from the Bonassama District Hospital (420 women, 241 men), 830 from the Deido District Hospital (451 women, 379 men), 442 from the Region 2 Littoral Military Hospital (226 women, 216 men), and 567 from the Nylon Brazzaville District Hospital (347 women, 220 men). 1.82\% (n=12) of women and 1.39\% (n=9) of men were infected with $S$. typhi at the Bonassama district hospital, $0.73 \%(\mathrm{n}=6)$ of women and 1.2\% $(\mathrm{n}=10)$ of men with $S$. typhi at Deido District Hospital, $3.84 \%(\mathrm{n}=17)$ of women and $2.26 \%(\mathrm{n}=10)$ of men simultaneously by $S$. typhi and S. paratyphi at the Region 2 Littoral Military Hospital and $0.88 \%(\mathrm{n}=5)$ of women and $1.06(\mathrm{n}=6)$ of the men of $S$. typhi at the District Hospital of Nylon Brazzaville. Regardless of the pathogen, the difference was significant at the $\mathrm{P}<0.05(\mathrm{P}=0.000 ; \mathrm{Phi}: 29.2 \%)$ threshold.

\subsection{Occurrence of typhoid fever and candidiasis in hospitals}

Figure (1) shows the evolution of typhoid fever, paratyphoid fever, and candidiasis in hospitals during 2019. It shows that the frequency of Candida spp., infection peaked relatively early in July (13\%) and fell in December (3.4\%). The difference between candidiasis and period is significant at the threshold of $\mathrm{P}<0.05(\mathrm{P}=0.007)$, with a low binding strength of $10.20 \%$, in contrast to $S$. typhi and $S$. paratyphi infection, which is not significant $(\mathrm{P}=0,112)$. The frequencies of $S$. typhi and S. paratyphi increased from June to August 2019, respectively S. typhi (9.7 \% January; $11.5 \%$ June), $S$. paratyphi (11.5 \% March, 10.2\% June; $15.2 \%$ July) and S. typhi and S. paratyphi (12.1\% March, 12.7\% June; $10.3 \%$ July). S. paratyphi was most infected in the [11-20] age group, $0.72 \%(\mathrm{n}=18)$ and $0.60 \%(\mathrm{n}=15)$ of men, and patients in the [21-30] age group, $0.68 \%(\mathrm{n}=17)$ of women and men; $S$. typhi infected more patients in the [11-20] age group, 3.2 \% $(\mathrm{n}=80)$ of women and $2.24 \%(\mathrm{n}=56)$ of men.

\subsection{Frequency of patients infected with $S$. typhi, $S$. paratyphi and Candida spp., and relationship between the pathogens}

The distribution of patients infected with S. typhi, S. paratyphi and Candida spp., according to age group and sex showed that $2.12 \%(\mathrm{n}=53)$ of women and $1.36 \%$ of men $(\mathrm{n}=34)$ were infected with $S$. paratyphi, $3.96 \%(\mathrm{n}=99)$ of women and $3.12 \%$ of men $(\mathrm{n}=78)$ with $S$. typhi, $3.88 \%(\mathrm{n}=97)$ of women and $2.80 \%$ of men $(\mathrm{n}=70)$ of S. typhi and Sparatyphi, $13.6 \%(\mathrm{n}=340)$ of women and $9.84 \%$ of men $(\mathrm{n}=246)$ of Candida spp., (Table 2). 
Table 1 Frequency of distribution of typhoid fever, paratyphoid fever and candidiasis fevers by gender and location.

\begin{tabular}{|c|c|c|c|c|c|c|c|c|c|}
\hline \multirow[b]{3}{*}{ Salmonella } & \multirow[b]{3}{*}{ Gender } & \multicolumn{8}{|c|}{ Candida spp } \\
\hline & & \multicolumn{2}{|c|}{$\underline{\mathrm{HDB}}$} & \multicolumn{2}{|c|}{$\underline{\text { HDD }}$} & \multicolumn{2}{|c|}{$\underline{\text { HMR2 }}$} & \multicolumn{2}{|c|}{ HDN } \\
\hline & & Négative & Positive & Négative & Positive & Négative & Positive & Négative & Positive \\
\hline TH+PTH(-) (\%) & $\mathrm{W}$ & $305(46,14)$ & $42(6,35)$ & $338(40,73)$ & $50(60,24)$ & $90(20,36)$ & $58(13,12)$ & $187(32,98)$ & $125(22,05)$ \\
\hline TH+PTH(-)(\%) & $\mathrm{M}$ & $183(27,68)$ & $18(2,72)$ & $276(33,25)$ & $56(67,47)$ & $102(23,07)$ & $45(10,18)$ & $120(21,16)$ & $74(13,05)$ \\
\hline PTH(+)(\%) & $\mathrm{W}$ & $20(3,02)$ & $4(0,61)$ & $7(0,84)$ & $3(0,36)$ & $12(2,72)$ & $3(0,68)$ & $2(3,52)$ & $2(3,52)$ \\
\hline PTH(+) $(\%)$ & $\mathrm{M}$ & $5(0,75)$ & $0(0,00)$ & $11(1,33)$ & $1(0,12)$ & $12(2,72)$ & $3(0,68)$ & $2(3,52)$ & $0(0,00)$ \\
\hline $\mathrm{TH}(+)(\%)$ & $\mathrm{W}$ & $21(3,17)$ & $12(1,82)$ & $34(4,9)$ & $6(0,73)$ & $5(1,13)$ & $3(0,68)$ & $13(2,3)$ & $5(0,88)$ \\
\hline $\mathrm{TH}(+)(\%)$ & $M$ & $14(2,11)$ & $9(1,36)$ & $13(1,57)$ & $10(1,2)$ & $12(2,72)$ & $7(1,58)$ & $7(1,23)$ & $6(1,06)$ \\
\hline $\mathrm{TH}+\mathrm{PTH}(+)(\%)$ & $\mathrm{W}$ & $15(2,26)$ & $1(0,15)$ & $9(1,08)$ & $4(0,48)$ & $38(8,59)$ & $17(3,84)$ & $8(1,41)$ & $5(0,88)$ \\
\hline $\mathrm{TH}+\mathrm{PTH}(+)(\%)$ & $\mathrm{M}$ & $11(1,67)$ & $1(0,15)$ & $9(1,08)$ & $3(0,36)$ & $25(5,66)$ & $10(2,26)$ & $8(1,41)$ & $3(0,53)$ \\
\hline Total $(\%)$ & $M+W$ & $574(86,84)$ & $87(13,16)$ & $697(83,98)$ & $133(16,02)$ & $296(66,97)$ & $146(33,03)$ & $347(61,20)$ & $220(38,80)$ \\
\hline
\end{tabular}

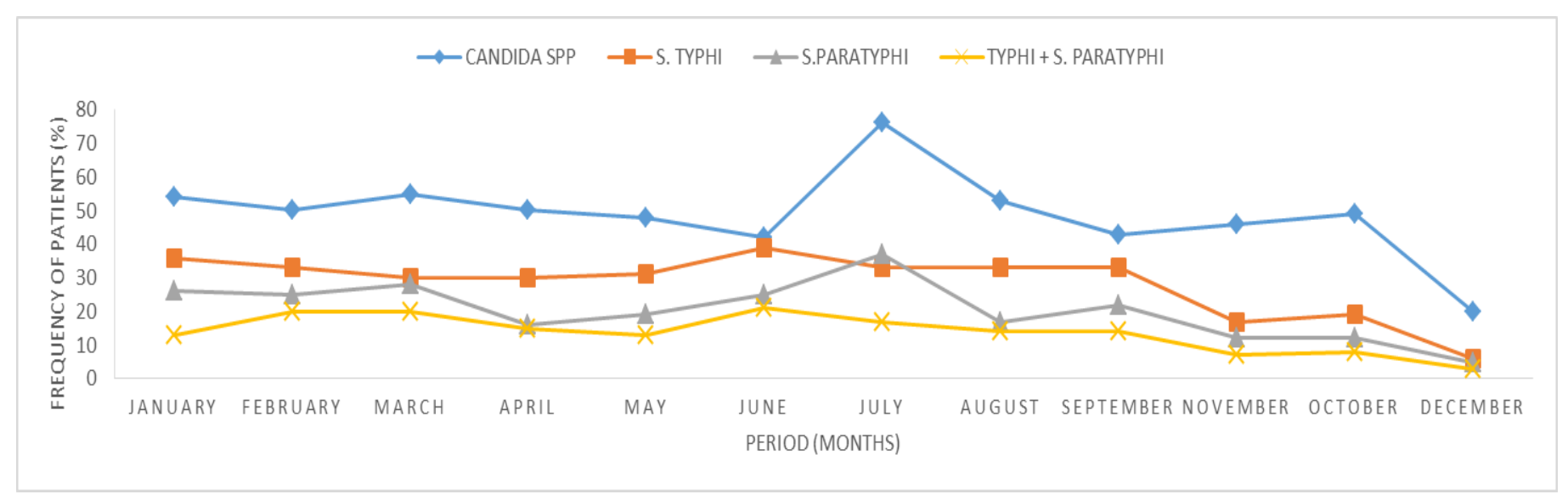

Figure 1 Occurrence of typhoid fever, paratyphoid and candidiasis in hospitals. 
International Journal of Science and Research Archive, 2021, 02(02), 110-119

Table 2 Frequency of patients infected with S. typhi, S. paratyphi and Candida spp., based on age group and sex.

\begin{tabular}{|c|c|c|c|c|c|c|c|c|c|c|}
\hline \multirow[t]{2}{*}{ AGE } & \multicolumn{2}{|c|}{ TH and PTH negative (\%) } & \multicolumn{2}{|c|}{ PTH positive (\%) } & \multicolumn{2}{|c|}{ TH positive (\%) } & \multicolumn{2}{|c|}{$\begin{array}{l}\text { TH and PTH } \\
\text { positive (\%) }\end{array}$} & \multicolumn{2}{|c|}{$\begin{array}{c}\text { Candida spp (\%) } \\
\text { positive }\end{array}$} \\
\hline & Woman & Man & Woman & Man & Woman & Man & Woman & Man & Woman & Man \\
\hline $11-20$ & $65(2.6)$ & $52(2.08)$ & $18(0.72)$ & $15(0.6)$ & $80(3.2)$ & $56(2.24)$ & $34(1,36)$ & $18(0.72)$ & $35(1.4)$ & $36(1.44)$ \\
\hline $21-30$ & $398(15.92)$ & $272(10.88)$ & $17(0.68)$ & $17(0.68)$ & $8(0.32)$ & $21(0.084)$ & $37(1,48)$ & $40(1.6)$ & $120(4.8)$ & $97(3.88)$ \\
\hline $31-40$ & $274(10.96)$ & $216(8.64)$ & $12(0.48)$ & $1(0.04)$ & $6(0.24)$ & $1(0.04)$ & $17(0,68)$ & $9(0.36)$ & $61(2.44)$ & $46(1.84)$ \\
\hline $41-50$ & $188(7.52)$ & $151(6.4)$ & $3(0.12)$ & $0(0.00)$ & $2(0.08)$ & $0(0.00)$ & $2(0,08)$ & $1(0.04)$ & $52(2.08)$ & $31(1.24)$ \\
\hline $51-60$ & $232(9.28)$ & $154(6.16)$ & $3(0.12)$ & $1(0.04)$ & $2(0.08)$ & $0(0.00)$ & $5(0,2)$ & $2(0.08)$ & $60(2.4)$ & $32(1.29)$ \\
\hline $61-70$ & $38(1.52)$ & $29(1.16)$ & $0(0.00)$ & $0(0.00)$ & $1(0.04)$ & $0(0.00)$ & $2(0,08)$ & $0(0.00)$ & $12(0.48)$ & $4(0.16)$ \\
\hline Frequency (\%) & $1195(47.8)$ & $874(34.96)$ & $53(2.12)$ & $34(1.36)$ & $99(3.96)$ & $78(3.12)$ & $97(3,88)$ & $70(2.8)$ & $340(13.6)$ & $246(9.84)$ \\
\hline
\end{tabular}

TH + PTH: S. typhi and S. paratyphi; PTH: S. paratyphi; TH: S. typhi;

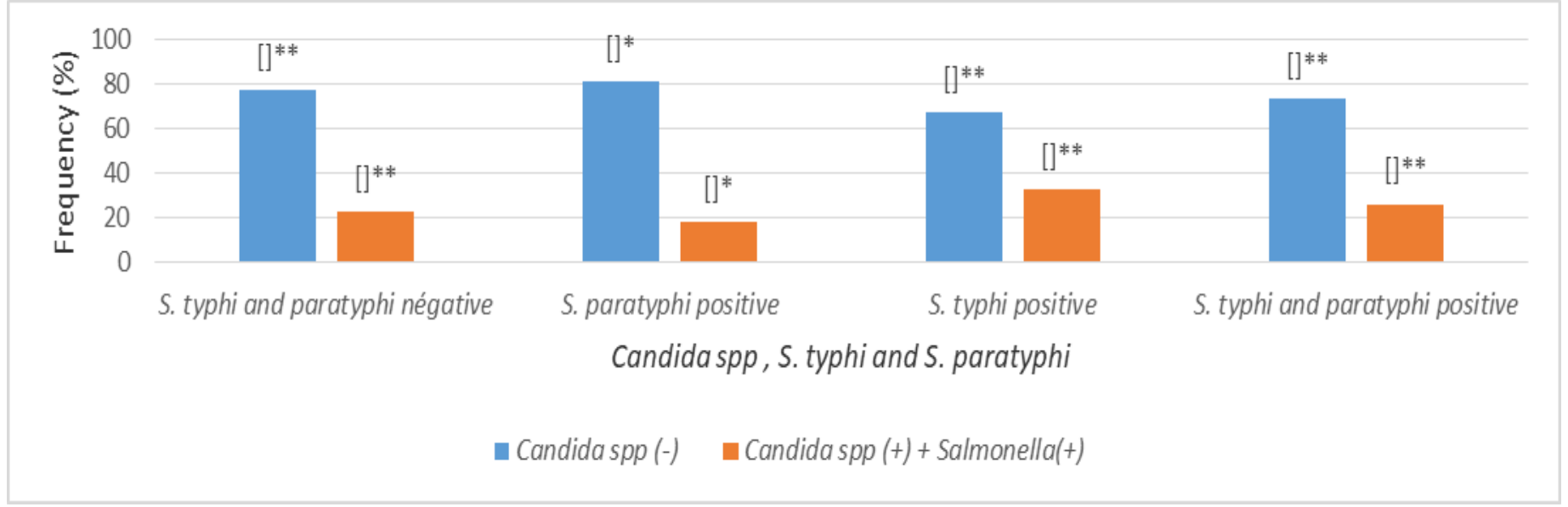

Figure 2 Relationship between S. typhi, S. paratyphi and Candida spp as a function of age group and sex; $(* *)$ : Significant difference at the threshold of $\mathrm{p}<0,05 ;(*)$ : none significant difference at the threshold of $\mathrm{P}<0,05$. 
S. paratyphi was highly infection in the age group [11-20], such as $0.72 \%(\mathrm{n}=18)$ and $0.60 \%(\mathrm{n}=15)$ of men, and patients aged [21-30] with $0.68 \%(\mathrm{n}=17)$ of women and men; $S$. typhi, infected more patients within [11-20] age group of which $3.2 \%(n=80)$ of women and $2.24 \%(n=56)$ of men;both pathogens affect simultaneously $1.36 \%(n=34)$ of women and $0.72 \%(\mathrm{n}=18)$ of the age group [11-20], $1.48 \%(\mathrm{n}=37)$ of women and $1.6 \%(\mathrm{n}=40)$ of men in the age group [21-30]; Candida spp. affect mainly $4.8 \%(\mathrm{n}=120)$ of women and $3.88 \%(\mathrm{n}=97)$ of men. Overall, $S$. typhi, $S$. paratyphi and Candida spp. infect more patients aged between [11-20], followed by those aged between [21-30]. However, the difference is significant at the threshold of $\mathrm{P}<0.05(\mathrm{P}=0.000$; Phi $=50.5 \%)$, between S. typhi, S. paratyphi, age group and sex. Nevertheless, it is significant at the $\mathrm{P}<0.05(\mathrm{P}=0.000)$ threshold, between $S$. typhi and age, $S$. paratyphi and age with a weak binding strength of $59.1 \%$ and $25.5 \%$ respectively. The infection of $S$. typhi is dependent on $S$. paratyphi and vice versa, with a binding strength of $59.10 \%$. The infection with $S$. typhi and S. paratyphi according to age is significant at $\mathrm{P}<0.05(\mathrm{P}=0.000, \mathrm{Phi}=59.10 \%)$. The study of Candida spp by age and sex shows a non-significant difference at the $\mathrm{P}<0.05(\mathrm{P}=0.079$; $\mathrm{Phi}=6.3 \%)$ threshold. However, the significance is positive between Candida spp., age and period $(\mathrm{P}=0.007)$, influenced by the age group [31-40] $(\mathrm{P}=0.005)$ with a low bond of $22.4 \%$, (Table 2$)$.

\subsection{Influence of Candida spp on $S$. typhi and $S$. paratyphi}

The infection with Candida spp., increases the percentage of infection of $S$. typhi from $7.08 \%$ (n $=177$ ) to $32.76 \%$, (n = $58)$, that of $S$. paratyphi from $3.48 \%(\mathrm{n}=87)$ to $18.4 \%(\mathrm{n}=16)$ and, that of $S$. typhi associated with $S$. paratyphi from $6.68 \%(n=167)$ to $26.35 \%(n=44)$, figure $(3)$.

\subsection{Components factors of infections of Candida spp, S. typhi and S. paratyphi}

The analysis of the relationship between S. typhi, S. paratyphi and Candida spp. shows that $18.72 \%(\mathrm{n}=468)$ of patients are infected with Candida spp. $0.64 \%(\mathrm{n}=16)$ with $S$. paratyphi and Candida spp., $2.32 \%(\mathrm{n}=58)$ with $S$. typhi and Candida spp, and $1.76 \%(\mathrm{n}=44)$ by $S$. typhi and S. paratyphi and Candida spp. The difference at the threshold of $\mathrm{P}<0.05$ is significant between Candida spp., $S$. typhi and $S$. paratyphi $(\mathrm{P}=0.003)$, with a correlation of $5.9 \%$. This difference is non-significant at the threshold of $\mathrm{P}<0.05(\mathrm{P}=0.849)$, between Candida spp. and S. paratyphi, (Table 2).

The correlation of the transformed values mainly shows that S. typhi, S. paratyphi and Candida spp. are correlated at $5.6 \%$, and Salmonella at age, $57.9 \%$. The measure of discrimination includes for dimension 1 the variables period, Candida spp. and sex, and for dimension 2, Salmonella and age. The frequencies of S. typhi and S. paratyphi increase from June to August respectively S. typhi (9.7 \% January; $11.5 \%$ June) mainly in patients in the age group [11-20], S. paratyphi (11.5\% March, 10.2 \% June; $15.2 \%$ July) and S. typhi and S. paratyphi $(12.1 \%$ March, $12.7 \%$ June; $10.3 \%$ July, and $5.1 \%$ October in women aged between [21-30]) (figure 4).

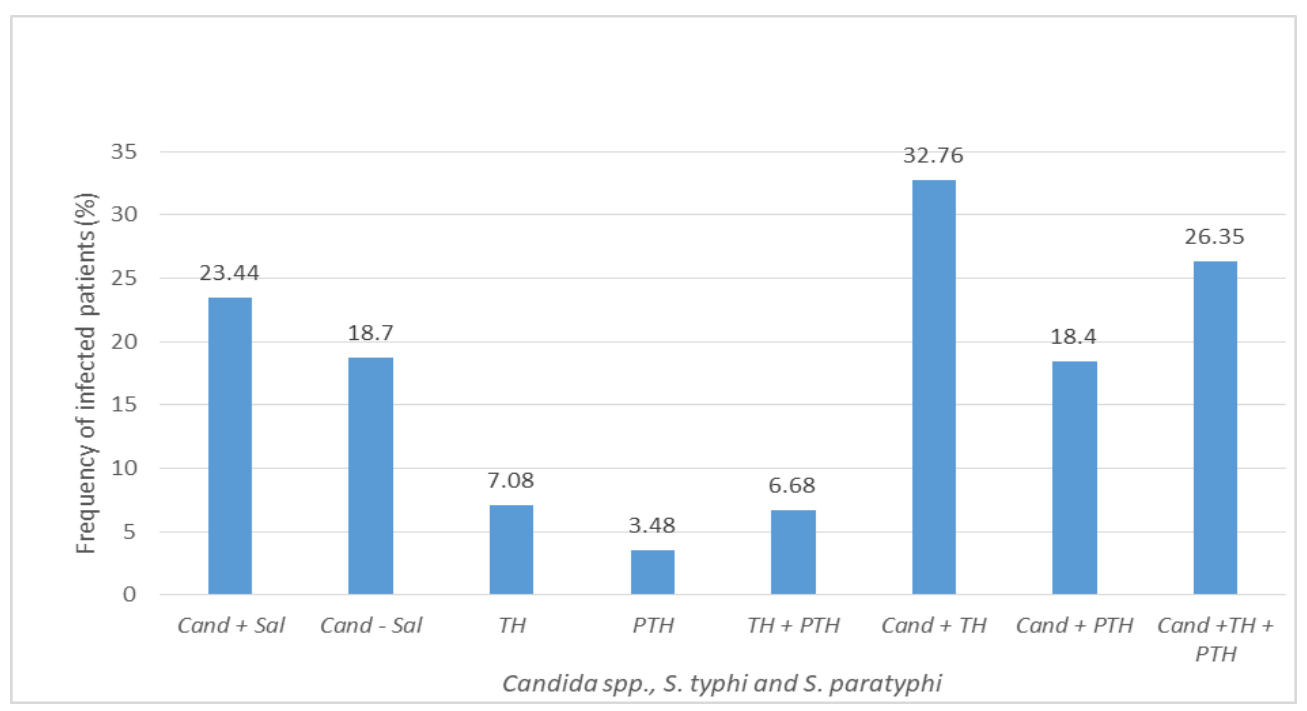

Figure 3 Influence of Candida spp on S. typhi and S. paratyphi 


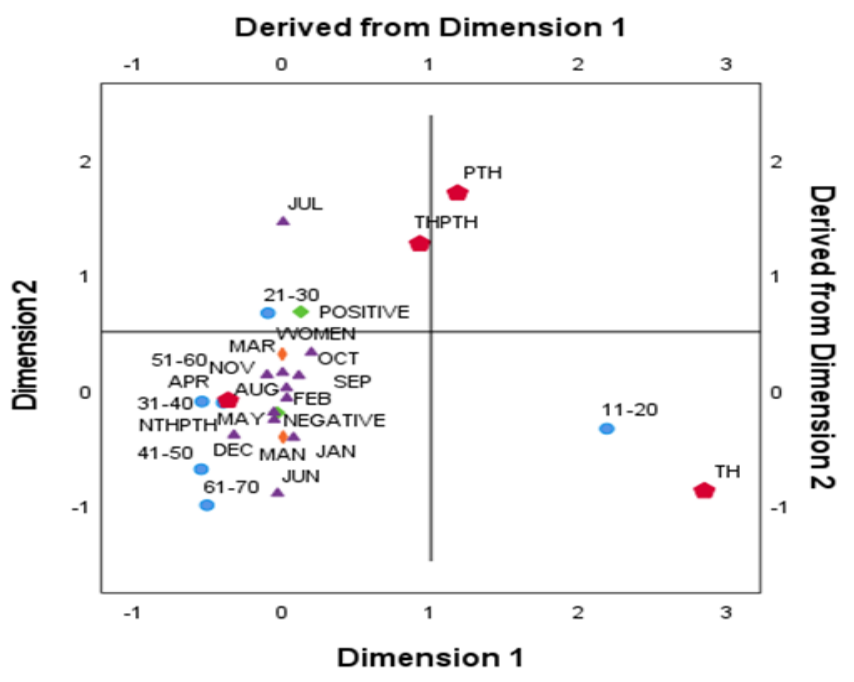

- AGE

- CANDIDA spp

- GENDER

$\triangle$ PERIOD

- SALMONELLA

Figure 4 Principal components factors of infections of candida spp, S. typhi and S. paratyphi based on sex, hospital age and period.

TH: S. typhi positive; PTH: S. paratyphi positive; THPTH: S. typhi and S. paratyphi positive; NTHPTH: S. typhi and S. paratyphi negative; JAN: January; FEB: February; MAR: March; APR: April; MAY: May; JUN: June; JUL: July; AUG: August; SEP: September; OCT: October; NOV: November; DEC: December.

March, September, August, November, January and April are more likely to be conducive to male aged group within [3170] infection to Candida spp., S. typhi and S. paratyphi.

\section{Discussion}

The aims of our study was to determine the relationship between Salmonella typhi and S. paratyphi with Candida spp.

The proportion of women in the study is higher than that of men (57.76\% compared to $42.24 \%$ of men), regardless of the health center. The percentage of positive infected cases with at least one form of Salmonella was $14.63 \%$ within women and $9.30 \%$ within men. This shows that women are more exposed to S. typhi, S. paratyphi or both pathogens simultaneously (Table 1). This could be explained by their regular contact with work surfaces or utensils during routine household workplace, on which Salmonella could have been easily established facilitating biofilms formation; among others women, especially those living in the neighborhoods with nothing but poor hygiene standards e.g. food exposed at roadsides, sometimes processing under critical cleaning conditions (home-made juices, food roasted on embers, peeled fruit, etc.); men are not at all to be left aside, they easily consume meals in coarse fastfood. However, the infection affects both men and women without distinction of gender.

The occurrence of infections with S. typhi, S. paratyphi and Candida spp., shows that typhoid and paratyphoid fever is an ubiquitous disease that occurs throughout the year. Nevertheless, the number of consultations and cases of illness has increased in January, March, April, June and July (figure 1). The behaviour of the disease is said to be linked to the recurrent presence of infection foci such as swamps due to the major floods generally recorded during this period, the proximity of markets with the galloping insalubrity, and promiscuity. Also, this period corresponds to the day after the festive season with the high risk of toxemics infections (January) [16]. The increase in the frequency of infection of candida spp. during this period in the stools of patients suggests a certain association of candidiasis with the disease, (figure 2).

Infection with $S$. typhi and S. paratyphi is independent of age group and sex, in contrast to infection with Candida spp. Age groups [11-20] and [21-30] appear to be more exposed to typical and paratypical salmonellosis [17, 18]. This is thought to be related to non-compliance of basic hygiene rules and sometimes lack of health education.

This would mean that basic hygiene rules are neglected and sometimes the lack of health education. Therefore, the reemergence of typhoid and paratyphoid fevers in patients would be influenced by the co-infection of pathogens involved 
in these pathologies with Candida spp. However, infection candida spp., would not be sufficient to bring S. paratyphi back to school in patients $[10,11]$.

Candida spp., infection is thought to increase the resurgence of typhoid and paratyphoid fevers in the population 4.63 (S. typhi) - 5.29 (S. paratyphi) times, compared with the results founded by Pate, [18] about co-infection of bacterial and filamentous fungal keratitis (3.2 times). Candida spp., and in particular Candida albicans create perforations in the intestine during infection which facilitate the penetration of S. typhi and S. paratyphi into the bloodstream, or are capable of producing chemical mediators that stimulate the growth of bacteria [11]. By metabolising certain molecules such as carbohydrates, they would provide energy for the bacteria to grow [19, 2021$]$. In addition, bacteria being able to form multiple associations in mixed biofilms consolidated by yeast adhesins, would escape antibiotics to reinfect the same patients, once the therapeutic and immune system offensive has been eliminated or diminished [22]. On the other hand, the frequency of Candida spp. decreases with co-infection with S. typhi and S. paratyphi. The bacteria are thought to produce substances that inhibit the hyphae of Candida spp., [9, 23].

Analysis of the correlation of transformed values shows that although S. typhi and S. paratyphi infection appears to be related to Candida spp. infection, it is weakly correlated at $5.6 \%$. S. typhi and S. paratyphi reinfection is also strongly correlated at $57.9 \%$ with age. This could be explained by the co-infection of $S$. typhi with S. paratyphi A, for which the duration of antibiotic therapy would be insufficient due to its underestimated duration in case of co-infection and partial treatment of the infection [24]. The ability of the immune system to regulate the reduction of the in vivo fungal load of Candida spp. through the intervention of the macrophage system and the establishment of immunological barriers. This would have a positive impact on the reduction of Salmonella infection $[24,25,26]$. Recurrent infection with $S$. typhi and S. paratyphi is associated with age, and infection with Candida spp. with time and sex.

\section{Conclusion}

This work aimed to determine the influence of Candida spp., on the reemergence of typhoid and paratyphoid fevers in patients. In short, the reappearance of typhoid and paratyphoid fevers is independent of sex and period. Those parameters influence the infection by Candida spp. Also in patients, simultaneous presence of S. typhi, S. paratyphi and Candida spp., would increase the percentage of reemergence of typhoid fever and paratyphoid fever in patients 4 to 5 times.

\section{Compliance with ethical standards}

\section{Acknowledgments}

We would like to thank the Regional Delegate for authorising us to carry out our study in the district hospitals of the city of Douala, as well as the directors of the district hospitals of Nylon Brazzavile, Deido, Bonassama and the Military Hospital of Region 2 of the Littoral Region, for their cooperation in this study. We are grateful to the Medical Biological Analysis Laboratory of the Military Hospital for his technical and material support, in particular to Doctor Eric NGOH AKWA. Special thanks to Doctor Jean Pierre ZO'ÓBO to the linguistic expertise of this document and to all the patients who agreed to participate in this study.

\section{Disclosure of conflict of interest}

The authors hereby certify that there is no conflicting interest of any kind in this study

\section{References}

[1] José Antonio Garbino, Wilson Marques Jr, Jaison Antonio Barreto, Carlos Otto Heise, Márcia Maria Jardim Rodrigues, Sérgio L. Antunes, Cleverson Teixeira Soares, Marcos Cesar Floriano, José Augusto Nery, Maria Angela Bianconcini Trindade, Noêmia Barbosa Carvalho, Nathália Carvalho de Andrada, Amilton Antunes Barreira, Marcos da Cunha Lopes Virmond. Primary neural leprosy: systematic review. Arq Neuropsiquiatr. 2013; 71(6): 397-404.

[2] Seghir Abdelfettah. Recherche de biofilms mixtes sur cathéters veineux périphériques au CHU de Tlemcen. Université Aboubekr Belkaïd -Tlemcen. 2015; 122. 
[3] Harriott MM, Noverr MC. Importance of Candida-bacterial polymicrobial biofilms indisease. Trends Microbiol. 2011; 19: 557-563.

[4] Hornby JM, Jensen EC, Lisec AD, Tasto JJ, Jahnke B, Shoemaker R, et al. Quorum sensing in the dimorphic fungus Candida albicans is mediated by farnesol. Appl Environ Microbiol. 2001; 6(7): 2982-2992.

[5] Waters CM, Bassler BL. Quorum sensing: cell-to-cell communication in bacteria. Annu Rev Cell Dev Biol. 2005; 21: 319-346.

[6] Eberhard A, Burlingame AL, Eberhard C, Kenyon GL, Nealson KH, Oppenheimer NJ. Structural identification of autoinducer of Photobacterium fishcheri luciferase. Biochemistry. 1981; 20: 9.

[7] Levison ME, Pitsakis PG. Susceptibility to experimental Candida albicans urinary tract infection in the rat. J Infect Dis. 1987; 155(5): 841-846.

[8] Hogan DA, Kolter R. Pseudomonas-Candida interactions: an ecological role for virulence factors. Science. 2002; 296: 2229-2232.

[9] Jarosz LM, Deng DM, VanderMei HC, Crielaard W, Krom BP. Streptococcus mutans competence-stimulating peptide inhibits Candida albicans hypha formation. Eukaryot Cell. 2009; 8(11): 1658-1664.

[10] Krause J, Geginat G, Tammer I. Prostaglandin E2 from Candida albicans stimulates the Growth of Staphylococcus aureus in Mixed Biofilms. PLoS ONE. 2015; 10(8): 17.

[11] Carlson E. Effect of strain of Staphylococcus aureus on synergism with Candida albicans resulting in mouse mortality and morbidity. Infect Immun. 1983; 42: 285-292.

[12] JC Pate, DB Jones, KR Wilhelmus. Prevalence and spectrum of bacterial co-infection during fungal keratitis. Br J Ophthalmol. 2006; 90: 289-292.

[13] World Health Organization. Typhoid vaccines: WHO position paper. 2018; 13.

[14] Vittal Mogasale, Brian Maskery, R Leon Ochiai, Jung Seok Lee, Vijayalaxmi V Mogasale, Enusa Ramani, Young Eun Kim, Jin Kyung Park, Thomas F. Burden of typhoid fever in low-income and middle-income countries: a systematic, literature-based update with risk-factor adjustment. Lancet Glob Health. 2014; 2: 570- 580.

[15] Global Antimicrobial Resistance Surveillance System (GLASS). Early implementation protocol for inclusion of Candida spp. 2019; 26.

[16] Gake B, Ngaroua C, Ebole Gake NM, Keugoung B, Mevoula Onana DE. Epidémie de la fièvre typhoide à GASA, Extreme -nord Cameroun en 2011. Médecine d'Afrique noire. Revue Medicale Internationale Panafricaine. 2015; 1(1): 8 .

[17] John J, Bavdekar A, Rongsen Chandola T. Estimating the incidence of enteric fever in children in India: a multisite, active fever surveillance of pediatric cohorts. BMC Public Health. 2018; 18(1): 6.

[18] Lozano RM, Naghavi K, Foreman S, Lim K, Shibuya. Global and regional mortality from 235 causes of death for 20 age groups in 1990 and 2010: a systematic analysis for the Global Burden of Disease Study 2010. Lancet 380. 2010; (9859): 2095-2128.

[19] Holmes AR, Vander Wieien P, Cannon RD, Ruske D, Dawes P. Candida albicans binds to saliva proteins selectively adsorbed to silicone. Oral Surg Oral Med Oral Pathol Oral Radiol Endod. 2006; 102(4): 488-494.

[20] Romano JD, Kolter R. Pseudomonas, Saccharomyces interactions: influence of fungal metabolism on bacterial physiology and survival. J. Bacteriol. 2005; 187(3): 940-948.

[21] Jenkinson HF, Douglas LJ. Interactions between Candida Species and Bacteria in Mixed Infections. In: Brogden KA, Guthmiller JM, editors. Polymicrobial Diseases. Washington (DC): ASM Press. Chapter 18. 2002; 1-70.

[22] Bassler BL. How bacteria talk to each other: regulation of gene expression by quorum sensing. Curr Opin Microbiol. 1999; 2: 582-587.

[23] El-Azizi MA, Starks SE, Khardori N. Interactions of Candida albicans with other Candida spp. And bacteria in the biofilms. J Appl Microbiol. 2004; 96: 1067-1073.

[24] Ankita Dutta, Deepak More, Ananya Tupaki-Sreepurna, Bireshwar Sinha, Nidhi Goyal, Temsunaro RongsenChandola. Typhoid and paratyphoid fever co-infection in children from an urban slum of Delhi. ID Cases 20. 2020; e00717: 4 . 
[25] Chandra Bhan Pratap, Gopal Kumar, Saurabh Kumar Patel, Vijay K Shukla, Kailash Kumar, Tej Bali Singh, Gopal Nath. Mix-infection of S. typhi and ParaTyphi A in Typhoid Fever and Chronic Typhoid Carriers: A Nested PCR Based Study in North India. J Clin Diagn Res. 2014; 8(11): DC09-DC14.

[26] Flaviano S Martins, Guillaume Dalmasso, Rosa ME Arantes, Anne Doye, Emmanuel Lemichez, Patricia Lagadec, Veronique Imbert, Jean-Francois Peyron, Patrick Rampal, Jacques R. Nicoli, Dorota C zerucka. Interaction of Saccharomyces boulardii with Salmonella enterica Serovar typhimurium Protects Mice and Modifies T84 Cell Response to the Infection. PLoS One. 2010; 5(1): 12. 